\title{
O ensino secundário no estado do Pará na Segunda República (1930-1945)
}

\author{
Tayana Helena Cunha Silva' (D) \\ Cesar Augusto Castro" (D)
}

\section{RESUMO}

O presente artigo busca analisar o ensino secundário público no Pará na Era Vargas. Nesse sentido, o objetivo geral é: identificar o cenário do ensino secundário no Pará a partir do cotidiano educativo do Colégio Paes de Carvalho/Ginásio Paraense. O procedimento metodológico deste estudo se caracteriza como documental tendo como fontes os documentos da referida instituição, como ofícios e horários de prova, além de mensagens dos governadores do Pará. $\mathrm{O}$ arcabouço teórico de análise das fontes foi composto por autores que discutem o cotidiano educativo do ensino secundário no Brasil na Segunda República. Os resultados do estudo apontaram que a instituição secundária paraense foi referência de educação da juventude do estado a partir de práticas curriculares orientadas por bases humanísticas, científicas e nacionalistas.

\section{PALAVRAS-CHAVE}

Colégio Paes de Carvalho; ensino secundário; estado do Pará. 


\title{
SECONDARY EDUCATION IN PARÁ STATE IN THE SECOND REPUBLIC OF BRAZIL (1930-1945)
}

\begin{abstract}
The present article seeks to analyze public secondary education in Pará State, during Getúlio Vargas' administration era. In this sense, the general objective is to identify the scenario of secondary education in Pará State from the educational routine of Colégio Paes de Carvalho (Paes de Carvalho School)/Ginásio Paraense (Paraense School). The methodological procedure of this study is characterized as documentary, having the documents of the institution as its sources, such as official letters and test schedules, as well as messages from the governors of Pará. The theoretical framework for analyzing the sources was composed by authors who discuss the educational routine of secondary education in Brazil during the Second Republic. The results show that the secondary education institution in Pará State was a reference for the education of the state's youth from curricular practices guided by humanistic, scientific, and nationalist bases.
\end{abstract}

KEYWORDS

Paes de Carvalho School; high school; Pará State.

\section{ENSEÑANZA SECUNDARIA EN EL ESTADO DE PARÁ EN LA SEGUNDA REPÚBLICA (1930-1945)}

\section{RESUMEN}

Este artículo busca analizar la enseñanza secundaria pública en el estado de Pará en la época del presidente Getúlio Vargas. En este sentido, el objetivo general es: identificar el escenario de la enseñanza secundaria de Pará a partir de la rutina educativa del Colegio Paes de Carvalho/Gimnasio Paraense. El procedimiento metodológico de este estudio se caracteriza como documental teniendo como fuentes los documentos de la referida institución tales como oficios y los horarios de prueba, así como los mensajes de los gobernadores de Pará. La estructura teórica de análisis de las fuentes estuvo compuesta por autores que discuten la rutina educativa de la enseñanza secundaria en Brasil en la Segunda República. Los resultados del estudio señalaron que la institución de enseñanza secundaria de Pará fue un referente para la educación de la juventud del estado a partir de prácticas curriculares guiadas por bases humanísticas, científicas y nacionalistas.

Colegio Paes de Carvalho; enseñanza secundaria; estado de Pará. 


\section{INTRODUÇÃO}

A oferta institucionalizada do ensino secundário no Pará foi iniciada ainda no século XIX, quando foi fundado, em 1841, na capital da Província, o chamado Liceu Paraense, que tinha grande representação para a sociedade por ser a única instituição pública de ensino secundário da capital. No período de 1930 a 1945, essa mesma instituição mudou de nome e passou a ser conhecida como Colégio Estadual Paes de Carvalho/Ginásio Paraense ${ }^{1}$.

Fundada no período imperial, essa instituição era direcionada à educação da juventude paraense, ministrando um ensino de fundo humanístico que prezava pela inserção da cultura, reforçando, assim, o princípio fundamental do ensino secundário.

Nesse sentido, apontamos como objetivo principal deste ensaio: identificar o cenário do ensino secundário no Pará a partir do cotidiano educativo do Colégio Paes de Carvalho/Ginásio Paraense no período histórico supracitado. De característica documental, este estudo foi realizado a partir das seguintes fontes: documentos da instituição, como ofícios e horários de prova, entre outros, que demonstravam as práticas ocorrentes naquele estabelecimento de ensino. Também utilizamos as mensagens dos governadores do estado do Pará, as quais anualmente descreviam a situação da educação pública do estado.

A busca pelo corpus documental deste estudo foi realizada no Arquivo Público do Estado do Pará (APEP)². As fontes da instituição foram localizadas em um arquivo específico do Colégio Paes de Carvalho contendo documentos como ofícios, decretos, horários de prova, etc., organizados na categoria denominada: fundo da secretaria de governo ${ }^{3}$.

Outra categoria de fonte que compôs os documentos analisados foram as mensagens dos governadores do estado, que apresentavam informações sobre a situação estadual em vários setores, como orçamento, obras públicas e também educação. Em cada mensagem, os gestores estaduais buscavam informar o Poder Legislativo sobre o andamento das ações de manutenção e desenvolvimento da educação nos ensinos primário, secundário e superior.

Nessa perspectiva, a análise das fontes foi fundamentada a partir de autores como Dallabrida (2009), Nunes (2000), Brito (2006), Souza (2009), entre outros que nos oportunizam compreender e contextualizar o cotidiano educativo do ensino secundário no Pará no período da Segunda República brasileira. O artigo está dividido em dois momentos. No primeiro, construímos uma discussão histórica a respeito do ensino secundário no Brasil desde as primeiras ações governamentais até

1 A nomenclatura da instituição no período de investigação se apresentava nos documentos por estas duas formas.

2 O Arquivo Público do Estado do Pará é um órgão estadual que preserva a memória do estado do Pará. Disponibiliza à sociedade paraense diversos documentos oficiais, como discursos de autoridades, jornais e outros tipos de arquivos que registraram a história do estado.

3 Organização documental adotada pelo órgão para reunir os documentos de diversas naturezas (economia, justiça, educação, etc.) emitidos no período da República. 
o período desta investigação. Em seguida, abordamos o cenário do ensino secundário no estado do Pará a partir das práticas educativas da primeira instituição pública de ensino secundário, o Colégio Paes de Carvalho/Ginásio Paraense.

\section{UMA BREVE LINHA DO TEMPO SOBRE O ENSINO SECUNDÁRIO NO BRASIL}

A história da educação registra que o ensino secundário foi iniciado no Brasil ainda no período colonial, inserido pelos jesuítas que instalaram os primeiros colégios secundários no país como uma das ações do processo de colonização liderado pela Companhia de Jesus. Segundo Nunes (2000, p. 37), a introdução dos "colégios secundários jesuítas nos núcleos de povoamento significava inserir uma cultura letrada num ambiente em que a oralidade predominava".

Essa cultura letrada foi disseminada a partir do conhecido método Ratio Studiorum, amplamente praticado pelos jesuítas nos colégios que dirigiam no território brasileiro. A educação ministrada pelos jesuítas se tratava do ensino de humanidades para os filhos de colonos, com lições de catequização reservadas aos indígenas (Nunes, 2000). Essa distinção do ensino ofertado pelos religiosos, sem abdicar da promoção da cultura escrita, em certa medida, promovia a diferenciação entre as classes sociais, o que caracterizou a história da proposta formativa do ensino secundário no Brasil Colônia.

O projeto de educação destinado ao ensino secundário sofreu as primeiras modificações depois da expulsão dos jesuítas pelo Marquês de Pombal, que, em 1759 , retirou os religiosos do comando da educação no Brasil. Os colégios de ensino secundário da Companhia de Jesus cederam espaço às chamadas aulas régias ou avulsas. Ainda que não mais dispusessem do monopólio da educação colonial, Zotti (2005) destaca que os princípios educativos jesuíticos e sua formação de base clássico-humanista ainda se faziam presentes nas aulas isoladas, por isso:

O ensino ministrado pelos jesuítas no segundo período de sua ação educativa, que diz respeito à educação da elite, é o que corresponde ao ensino de tipo secundário. $\mathrm{O}$ objetivo era a formação de padres, de quadros para a administração do empreendimento colonial e do Estado e educar as classes dominantes. (Zotti, 2005, p. 31)

Nessa direção, as chamadas aulas régias, que foram instituídas em 1772, se configuravam no ensino de humanidades, no ensino literário e religioso, além de lições de latim, grego, filosofia, entre outras disciplinas ministradas individualmente por cada professor. Essa lógica formativa de fundo clássico-humanista, que objetivava educar para proporcionar às elites a chamada cultura geral, perdurou por todo o período colonial e, ao adentrar no Império, foi confrontada por uma nova perspectiva de educação científica para o ensino secundário que será melhor discutida mais adiante (Zotti, 2005).

Foi no Império que a oferta do ensino secundário tomou uma nova forma. Nesse período da história do Brasil, esse nível de ensino começou a institucionalizar- 
-se. Destinava-se a formar uma elite ilustrada, com a oferta da chamada educação desinteressada, que provia uma cultural geral e a manutenção das bases humanísticas advindas do ensino jesuítico do período colonial (Nunes, 2000).

Assim, uma das primeiras iniciativas de organização do ensino secundário na esfera pública - a mais emblemática nessa linha do tempo - foi a fundação, em 2 de dezembro de 1837, do Colégio Pedro II, que anteriormente havia funcionado como Seminário de São Joaquim e também abrigado o antigo Seminário dos Órfãos de São Pedro. Assim, esse colégio foi a primeira instituição pública de ensino secundário no país legalizada pelo governo imperial (Pessanha e Brito, 2014).

Nesse sentido, o pioneirismo do Colégio Pedro II na oferta do ensino secundário no Brasil Império o tornou referência para as instituições que posteriormente viriam a se formar no país para oferecer esse mesmo nível de ensino. Além disso, para Zotti (2005), a criação do colégio também representou uma ação do poder imperial para substituir as aulas régias do tempo da colônia (que basicamente correspondiam ao ensino secundário), assim:

O Colégio Pedro II acabou impondo um modelo curricular padrão para o ensino secundário. Por isso, o Colégio Pedro II é o marco do ensino secundário brasileiro no Império e sua análise pode nos proporcionar a compreensão da função social desse tipo de ensino, bem como compreender como essa função materializa-se no seu currículo. (Zotti, 2005, p. 35)

O ensino secundário tinha a finalidade de formar os indivíduos que conduziriam o país ou, como definiu Ghiraldelli Jr. (2008), formar as "elites condutoras" que iriam dirigir o país nos mais diversos setores da vida social e, por essa razão, necessitavam de uma formação mais sofisticada.

Diante dessas finalidades atribuídas ao ensino secundário, Ghiraldelli Jr. (2008) corrobora que o seu objetivo era educar aqueles que futuramente deveriam ser os responsáveis pelas mudanças na vida social e influenciar as massas de certa maneira.

Além disso, é importante destacar outro ponto de grande representatividade na história do ensino secundário público no Brasil: o ato adicional de 1834, que delegou às províncias a tarefa de gerir os níveis primário e secundário de educação, ficando também livres para legislar em suas localidades sobre esse grau de educação (Pessanha e Brito, 2014).

Com base nessa prerrogativa legislatória, o Colégio Pedro II tornou-se modelo para as províncias na criação de suas instituições secundárias, conhecidas como liceus. Contudo, essas instituições não obtiveram muito êxito por causa do baixo contingente de alunos e do número insuficiente de docentes capacitados para "atender às exigências impostas pela organização do trabalho didático proposta para o ensino secundário" (Pessanha e Brito, 2014, p. 242).

A respeito do currículo adotado nesses estabelecimentos, Zotti (2005) aponta que, com o referido ato adicional, o programa do ensino secundário se estruturou duplamente: a primeira forma se tratava de um sistema regular ofertado no Colégio Pedro II e nos liceus provinciais, e a outra correspondia aos chamados 
exames parcelados e cursos preparatórios. Ainda de acordo com a autora, o primeiro sistema basicamente se destinava aos filhos da elite, corroborando a premissa de que o ensino secundário tinha a função de formar os futuros condutores da elite política do país.

Já o segundo sistema, de exames parcelados e cursos preparatórios, permitia que o candidato ingressasse no ensino superior antes mesmo de concluir os estudos secundários. Em síntese, ambos os sistemas, ainda que diferenciados, traziam consigo marcas da cultura europeia, sobretudo no que concerne ao ensino clássico-humanista, inicialmente instaurado pelos jesuítas e continuamente praticado no Império na formação do jovem provido de cultura, fruto das elites que historicamente detinham em suas mãos "a condução da educação, não foram capazes, ou não convinha a elas, enfrentar de modo direto nossas realidades e buscar soluções e caminhos condizentes com as necessidades do país" (Zotti, 2005, p. 35).

Ghiraldelli Jr. (2008) destaca que o tipo de currículo praticado no ensino secundário durante o Império submeteu o Colégio Pedro II a diversas reformas curriculares. E tais alterações demonstravam certa variação entre a formação humanística e a científica.

Tal oscilação se deveu às disputas do ideário positivista contra o ideário humanista de herança jesuítica. Quando o ideário positivista levava vantagem, na medida em que caía nas graças dos gostos intelectuais da época, o Colégio Pedro II passava a incorporar mais disciplinas científicas. Quando os positivistas perdiam terreno voltava-se para uma grade curricular de cunho mais literário. (Ghiraldelli Jr., 2008, p. 30)

Outra questão marcante na história do ensino secundário público no Brasil, ainda no Império, diz respeito à Reforma Leôncio de Carvalho, que, em 1879, por meio do decreto 7.247, estabeleceu a liberdade de ensino nos níveis primário e secundário. No cenário dessa reforma, especificamente no que concerne ao ensino secundário, a legislação não previa obrigatoriedade da frequência às aulas e permitia aos alunos aprenderem da maneira que julgassem mais oportuna para si e, posteriormente, se submeterem aos exames característicos desse nível de ensino (Ghiraldelli Jr., 2008).

Portanto, podemos observar que a história do ensino secundário público, no Brasil, registrou uma tímida organização que basicamente se voltava aos exames e cursos preparatórios e aos liceus, que nem sempre funcionavam bem. Tal realidade, segundo Ghiraldelli Jr. (2008), definiu o ensino secundário como um mero sistema de exames, e não como um projeto de educação pública.

\section{A REESTRUTURAÇÃO DO ENSINO SECUNDÁRIO NA REPÚBLICA}

A configuração vigente no ensino secundário que privilegiava especialmente os estudos literários, ou seja, a formação da cultura geral para educar os filhos das elites do país, assim como a prática dos exames, permaneceu em vigor por quase toda a Primeira República. Porém, conforme aponta Dallabrida (2009), as ações 
destinadas ao ensino secundário nesse período foram quase inexistentes e sua oferta se concentrou nas instituições católicas, que instituíram vários colégios secundários.

Entre as poucas ações destinadas ao secundário durante a Primeira República, Pessanha e Brito (2014) apontam o estabelecimento de algumas reformas que tentaram regulamentá-lo. Dentre essas legislações, destacam-se as reformas Epitácio Pessoa (1901), Rivadávia Corrêa (1911) e Carlos Maximiliano (1915), que versavam sobre os ensinos secundário e superior.

As mudanças mais efetivas no ensino secundário foram registradas na Segunda República, a partir de 1930, quando Getúlio Vargas assumiu a presidência, instituindo o governo provisório, quando estabeleceu as mudanças mais significativas no campo da educação. Entre essas modificações, destaca-se a criação do Ministério da Educação e Saúde Pública, no fim de 1930, com Francisco Campos como primeiro-ministro, que, em 1931, criou o Conselho Nacional de Educação e promoveu a reorganização do ensino secundário e superior (Dallabrida, 2009).

Entre as alterações, podemos listar a maior inserção do conhecimento científico com um currículo de base clássico-humanística. Essa mudança ficou mais visível na reorganização do ensino secundário, conhecida como a Reforma Francisco Campos, regulamentada pelo Decreto $\mathrm{n}^{\circ} 18.890$, de 18 de abril de 1931 (Brasil, 1931).

A Reforma Francisco Campos teve grande representatividade na história do ensino secundário público no Brasil, pois, segundo Dallabrida (2009), legalizou e consolidou a organização desse nível de ensino. Além disso, tal reforma possibilitou, mesmo que de forma tardia, se comparada à dos países europeus, ocorrida ainda no século XIX, a modernização do ensino secundário brasileiro.

Esse processo de modernização do secundário foi construído por um conjunto de medidas que, segundo Dallabrida (2009), lhe propiciaram maior estruturação, com o objetivo de formar os jovens alunos para se tornarem indivíduos ordeiros e produtivos em consonância com a sociedade que estava em construção naquele momento: capitalista e disciplinada. Entre as ações de modernização, estavam:

O aumento do número de anos do curso secundário e sua divisão em dois ciclos, a seriação do currículo, a frequência obrigatória dos alunos às aulas, a imposição de um detalhado e regular sistema de avaliação discente e a reestruturação do sistema de inspeção federal. (Dallabrida, 2009, p. 185)

Ainda de acordo com o mesmo autor, além dessas medidas, outra ação de relevância para o ensino secundário produzida pela Reforma Francisco Campos foi a extinção dos exames parcelados. Com a frequência obrigatória, surgiram os exames finais, que dispunham de logística semelhante à aplicada no ensino primário.

Porquanto, a organização prevista pela referida Reforma articulou o nível secundário de modo a aumentar o seu tempo de duração, que passou de 5 para 7 anos, além de distribuir o tempo de educação em dois ciclos: o primeiro, denominado de fundamental, e o segundo, correspondente à formação complementar, com durações de cinco e dois anos, respectivamente (Dallabrida, 2009). 
Ainda que extensa, a formação oferecida no ciclo fundamental era composta por uma instrução comum ministrada a todos os alunos. Uma certa diferenciação ocorria no ciclo complementar, pois, nessa fase formativa, o curso apresentava um currículo preparatório que previa, após a sua conclusão, a possibilidade de ingresso no ensino superior nos cursos jurídicos, de saúde (medicina, farmácia e odontologia), engenharia e arquitetura (Dallabrida, 2009).

Nesse sentido, o currículo proposto pela Reforma Francisco Campos se constituiu por disciplinas literárias e científicas, conforme apontam os artigos $3^{\circ} \mathrm{e}$ 4o do Decreto no 18.890, de 18 de abril de 1931:

Art. $3^{\circ}$ Constituirão o curso fundamental as matérias abaixo indicadas, distribuídas em cinco anos, de acordo com a seguinte seriação:

$1^{a}$ série: Português - Francês - História da civilização - Geografia - Matemática - Ciências físicas e naturais - Desenho - Música (canto orfeônico).

$2^{\mathrm{a}}$ série: Português - Francês - Inglês - História da civilização - Geografia Matemática - Ciências físicas e naturais - Desenho - Música (canto orfeônico). $3^{a}$ série: Português - Francês - Inglês - História da civilização - Geografia - Matemática - Física - Química - História natural - Desenho - Música (canto orfeônico). $4^{a}$ série: Português - Francês - Inglês - Latim - Alemão (facultativo) - História da civilização - Geografia - Matemática - Física - Química - História Natural - Desenho. 5a série: Português - Latim - Alemão (facultativo) - História da civilização Geografia - Matemática - Física - Química - História natural - Desenho.

Art. $4^{\circ} \mathrm{O}$ curso complementar, obrigatório para os candidatos à matrícula em determinados institutos de ensino superior, será feito em dois anos de estudo intensivo, com exercícios e trabalhos práticos individuais, e compreenderá as seguintes matérias: Alemão ou Inglês. Latim, Literatura, Geografia, Geofísica Cosmografia, História da Civilização, Matemática, Física, Química, História natural, Biologia geral, Higiene, Psicologia e Lógica, Sociologia, Noções de Economia e Estatística, História da Filosofia e Desenho. (Brasil, 1931, p. 1)

Mesmo com toda a modernização da Reforma Francisco Campos, o currículo do ensino secundário ainda apresentava um caráter enciclopédico, no entanto, as ciências exatas surgiam no ciclo fundamental, como confirma Nunes (2000), quando analisa:

no ciclo fundamental, os estudos científicos apresentavam, diferentemente da Reforma Benjamin Constant, na qual houve o predomínio das matemáticas, o domínio das ciências físicas e naturais. O curso complementar de currículo diferenciado quanto à destinação dos alunos também assumia ares de um enciclopedismo especializado. (Nunes, 2000, p. 44)

Assim, as ciências se fizeram mais presentes no currículo do ensino secundário a partir da República e, especificamente, com a reforma supracitada, pois, embora já existissem no período do Império, as ciências não ocupavam tanto espaço na formação dos jovens secundaristas e acabavam por aparecer mais "no discurso do 
que na prática pedagógica do Colégio Pedro II e, por extensão, nos demais colégios de ensino secundário" (Nunes, 2000, p. 43).

Nesse sentido, além de a Reforma Francisco Campos estabelecer um conjunto maior de disciplinas científicas coadunadas a uma proposta ainda predominantemente enciclopédica, a nova organização do ensino secundário também permitiu, de acordo com Dallabrida (2009), fixar em todo o território nacional uma metodologia de trabalho, assim como a aplicação de procedimentos didático-pedagógicos ${ }^{4}$.

Todo esse movimento de reorganização não se limitou apenas a essa reforma. Após a gestão de Francisco Campos, Gustavo Capanema assumiu o Ministério da Educação e Saúde Pública e, em 1942, deu continuidade à reestruturação curricular do ensino secundário, estabelecendo um conjunto de reformas que ficaram conhecidas como leis orgânicas do ensino.

Esse conjunto de reformas educacionais foi implementado durante o Estado $\mathrm{Novo}^{5}$, entre os anos de 1942 e 1946. A Reforma Capanema, como foi denominada, reestruturou os ensinos primário, secundário, industrial, comercial, agrícola e normal por meio de decretos. A reestruturação trouxe em sua essência o aspecto elitista e conservador do novo regime ditatorial estabelecido pela Constituição de $1937^{6}$ (Ghiraldelli Jr., 2008).

As leis orgânicas estabeleceram o dualismo educacional incentivado pela política centralizadora do governo. Essa particularidade do cenário da educação, sobretudo no ensino secundário público, resultou na constituição de um sistema de educação ramificado que reforçou a diferença de classes.

Nas letras da Reforma Capanema, tratava-se de organizar um sistema de ensino bifurcado, com o ensino secundário público destinado, nas palavras do texto da lei, às "elites condutoras", e um ensino profissionalizante para outros setores da população. A Reforma Capanema queria criar "elites condutoras" a partir de um dado setor já privilegiado economicamente sem levar em conta o processo escolar pelo qual passaria cada indivíduo e que, segundo o credo liberal, poderia elevar os mais pobres a condições melhores. (Ghiraldelli Jr., 2008, p. 82)

4 É importante destacar que a Reforma Francisco Campos foi estabelecida no momento em que o ideário da Escola Nova estava em evidência no Brasil, de modo que o Ministro da Educação (Francisco Campos) buscou inserir os princípios escolanovistas na reforma secundária (Dallabrida, 2009). No entanto, o ensino secundário se distanciou desse movimento pedagógico a partir da reforma subsequente, quando a educação pública passou a enfatizar a diferença de classes no Estado Novo.

5 O Estado Novo foi um período ditatorial instalado no Brasil entre os anos de 1937 e 1945 e teve como presidente Getúlio Vargas. Foi reconhecido como uma ditadura por conta de ações como o fechamento do Congresso Nacional e a ausência de eleições, entre outros fatores. No que se refere à história da educação, o Estado Novo se constituiu em um período marcante em razão do dualismo educacional que evidenciava o caráter elitista da educação (Ghiraldelli Jr., 2008).

6 A Carta Magna de 1937 inaugurou a ditadura do Estado Novo e revogou os princípios democráticos na Constituição de 1934. Em relação ao campo da Educação, a Constituição de 1937 desobrigava o Estado de sua responsabilidade com o ensino público (Ghiraldelli Jr., 2008). 
Ademais, o mesmo autor destaca que a Lei Orgânica do Ensino Secundário, promulgada em 1942, seguia o regime autoritário do governo e tinha o objetivo de formar a juventude que iria dirigir o país. Para tanto, a educação secundária, naquele período, foi novamente reorganizada e dispôs de um amplo programa que formava a partir da cultura geral e da promoção do ensino patriótico (Ghiraldelli Jr., 2008).

Pessanha e Brito (2014) elucidam que a nova reorganização do currículo do ensino secundário definiu o curso ginasial e o colegial, este último subdividido em clássico e científico. Assim se apresentava currículo do ensino secundário no curso ginasial:

Art. 10. O curso ginasial abrangerá o ensino das seguintes disciplinas:

I. Línguas:

1. Português.

2. Latim

3. Francês.

4. Inglês.

II. Ciências:

5. Matemática.

6. Ciências naturais.

7. História geral.

8. História da Brasil.

9. Geografia geral.

10. Geografia do Brasil.

III. Artes:

11. Trabalhos manuais.

12. Desenho. (Brasil, 1942, p. 2)

O curso colegial, que se ramificava em clássico e científico, tinha um currículo era semelhante ao curso ginasial, com exceção das disciplinas de latim e grego, que eram ministradas apenas no curso clássico, e o ensino do desenho, exclusivo para o curso científico.

Art. 12. As disciplinas pertinentes ao ensino dos cursos clássico e científico são as seguintes:

I. Línguas:

1. Português.

2. Latim.

3. Grego.

4. Francês.

5. Inglês.

6. Espanhol.

II. Ciências e Filosofia:

7. Matemática.

8. Física.

9. Química. 
10. Biologia.

11. História geral.

12. História do Brasil.

13. Geografia geral.

14. Geografia do Brasil.

15. Filosofia.

III. Artes:

16. Desenho. (Brasil, 1942, p. 3)

A respeito dessa nova organização curricular, Dallabrida (2009) assinala que a Lei Orgânica do Ensino Secundário também representou a reconstituição da Reforma Francisco Campos. Por isso observa-se que o currículo conservou a função de preparar os indivíduos para o ensino superior, daí ter um programa extenso e de elevado nível de exigência.

Por fim, ainda de acordo com Dallabrida (2009), essa versão do ensino secundário se manteve em vigor até o início da década de 1970, quando foi novamente reorganizado e passou a ser denominado como $1^{\circ}$ grau, instituído a partir da "fusão do curso primário com o ciclo ginasial, e o $2^{\circ}$ grau, formado pelo ciclo colegial" (Dallabrida, 2009, p. 187).

No mais, o histórico do ensino secundário público no Brasil demonstra que esteve submetido a diversas modificações desde o Império e se consolidou, no período da República, por um conjunto de reformas do ponto de vista da legislação e, consequentemente, da oferta. Contudo, um fato interessante nessa linha do tempo é a permanência do objetivo formativo do secundário: educação para a elite, que deveria ser instruída nos pressupostos da cultural geral e que, com o passar do tempo, em certa medida se adequou à realidade, mas sem perder a sua essência.

Diante desse fato, podemos observar que os estados acompanharam as transformações no ensino secundário desde a criação dos liceus, que buscavam equiparação ao Colégio Pedro II, até o estabelecimento dos ginásios em diversas capitais do Brasil. O estado do Pará também se associou a essas alterações. O exemplo mais emblemático de instituição secundária do estado foi o Ginásio Paraense/ Colégio Paes de Carvalho, que se constituiu em referência de educação dos jovens paraenses, como veremos a seguir.

\section{ENSINO SECUNDÁRIO NO PARÁ NA SEGUNDA REPÚBLICA: EDUCAÇÃO DA JUVENTUDE PARAENSE NO COLÉGIO PAES DE CARVALHO/GINÁSIO PARAENSE (1930-1945)}

O Colégio Paes de Carvalho/Ginásio Paraense foi criado durante a instituição dos liceus nas diversas províncias brasileiras, ainda no período imperial. Foi fundado como Liceu Paraense pela Lei no 97, de 28 de julho de 1841, que regimentou os ensinos primário e secundário na província paraense. A recém-criada instituição secundária na capital paraense ofertava os cursos de humanidades e de comércio (França, 1997). 
Ainda segundo França (1997), a fundação de um estabelecimento de educação secundária no estado ocorreu em razão da situação em que se encontrava no estado: havia certo descaso com esse nível formativo que se resumia às aulas régias, disponibilizando somente "uma aula de Filosofia Racional e Moral, uma de Retórica, quatro de Latim e uma de Francês, encontrando-se estas últimas sem provimento" (França, 1997, p. 120).

Sendo assim, o Liceu/Ginásio Paraense, atualmente Colégio Paes de Carvalho, foi a primeira instituição pública de ensino secundário do Pará originada ainda no período imperial. A instituição ganharia maior visibilidade no período da República, quando, de acordo com Araújo (2017), se tornou referência na formação dos filhos da elite paraense.

Portanto, na Segunda República, o Colégio Paes de Carvalho estava inserido em um amplo contexto de mudanças que ocorriam no país nas mais diversas esferas, entre as quais destacamos a educação. Naquele período da história, entre os fatos que alteraram o cenário da educação pública, houve a divulgação do manifesto dos pioneiros da educação nova, as constituições de 1934, de caráter democrático que assegurava o direito à educação, e de 1937, que acabou, com tal prerrogativa, de certa maneira prejudicando a democratização do acesso à educação (Ghiraldelli Jr., 2008).

Nesse contexto, o Colégio Paes de Carvalho/Ginásio Paraense, como instituição de instrução secundária, se equiparava ao Colégio de Pedro II desde a sua fundação e manteve tal equiparação no período de instauração dos ginásios. Isso porque, ainda que as configurações do ensino secundário tivessem sofrido modificações, as instituições secundárias estaduais, entre elas o estabelecimento paraense, deveriam estar em conformidade com o agora Ginásio Nacional (antigo Colégio Pedro II) (Nunes, 2000).

A consonância das práticas educativas no Ginásio Paraense com a instituição nacional modelo foi evidenciada no discurso do governador do estado da época, Dr. José Malcher, à assembleia legislativa, em 1936. Sobre a referida instituição de ensino, afirmou que o estabelecimento estava em sintonia com as alterações propostas para o ensino secundário e ainda assinalou:

Obedecendo a nova orientação do ensino secundário, elaborada pelo Ministério da Educação e Saúde Publica, creamos, por decreto n. 1950, de 3 de março do corrente anno, o Curso Complementar, funcionando no Gymnasio Paraense, com um total de 97 alunos. Convem notar que no Norte do Brasil o Pará é um dos únicos Estados a manter este curso. [...] Annexo ao mesmo estabelecimento funciona o curso de adaptação, destinado a preparar alumnos para o curso fundamental, constituindo este trabalho obra de valor. (Pará, 1936, p. 99)

O excerto acima ainda nos aponta que, além de seguir as mudanças legais, o Colégio Paes de Carvalho/Ginásio Paraense ofertava cursos preparatórios para o ingresso no ensino secundário. Esse curso é historicamente conhecido como os exames de admissão que, de acordo com Nunes (2000), figuravam como uma 
espécie de caminho decisivo na formação dos indivíduos, como uma ponte entre o ensino primário e o ensino secundário. Além disso, a aprovação nesse exame era sinônimo de ascensão social, o que reforçava o papel atribuído à educação secundária pública.

Ainda que ofertasse o curso preparatório para o ingresso no ensino secundário, não se pode perder de vista que o foco da instituição secundária paraense estava voltado a educar a juventude da sociedade local. Dessa forma, o Colégio Paes de Carvalho/Ginásio Paraense dispunha de um currículo de base humanística que, ao mesmo tempo, procurava contemplar o ensino científico e incutir o sentimento de patriotismo e civilidade durante o processo educativo.

\section{CURRÍCULO E PRÁTICAS EDUCATIVAS NO COLÉGIO PAES DE CARVALHO/GINÁSIO PARAENSE}

O currículo praticado na instituição no ano de 1930 seguia as orientações federais e, mais especificamente, a Reforma Francisco Campos, buscando a tão comentada modernização almejada com essa reorganização curricular. Portanto, para se manter como referência na educação secundária, a instituição comunicou, por meio de ofício ao interventor estadual, em 1931, que a adoção da lei federal de reorganização desse nível de ensino seria realizada em prazo mínimo estipulado, como aponta o excerto a seguir:

Para que o Gymnasio possa gosar dos favores da equiparação federal ou seja da faculdade de preparar alumnos para as escolas superiores de todo o Brasil, faz-se mister adoptar a nova reforma do ensino baixada com o decreto $\mathrm{n}^{\circ}$ 19.890, de 18 de abril ultimo e cuja applicação neste estabelecimento deve ser feita dentre os 30 dias seguintes a publicação da lei acima referida. (Gymnasio Paraense, 1931)

Esse decreto de fato impactou a organização curricular do Colégio Paes de Carvalho/Ginásio Paraense, pois a referida legislação orientou a exclusão da cadeira de latim do $1^{\circ}$ ano, o que causaria transtorno a outro docente, como mostra o trecho do documento da direção da instituição ao interventor do estado demonstrando preocupação com o destino da instituição e da formação dos jovens paraenses:

Conforme deliberação do Exmo. Snr. Ministro da Educação a nova reforma attingirá exclusivamente o $1^{\circ}$ e 2 anno, trazendo assim a suppressão da cadeira de latim do $1^{\circ}$ anno e, ao cathedrático dessa disciplina, diminuindo nas horas de trabalho, se poderia entregar, sem mais ônus ao Thesouro, uma turma de francez, uma vez que a referida cathedrática está sobrecarregada de trabalho [...] Verifica V. Exa. o interesse desta directoria em cooperar para o engrandecimento e conceito do governo fecundo e honesto de V. Exa. [...] pois a não adoptação da reforma importaria num verdadeiro fracasso administrativo de consequências prejudiciaes para toda mocidade paraense. (Gymnasio Paraense, 1931) 
Além da exclusão dessa disciplina, podemos observar no trecho do ofício que, para manter todas as atividades no estabelecimento de ensino, por vezes a direção da instituição recorria ao interventor do estado para garantir o funcionamento de algum serviço que pudesse estar comprometido. Porque, uma vez prejudicado, correria o risco de não proporcionar educação de qualidade à sociedade paraense. Em vista disso, nota-se a importância do Colégio Paes de Carvalho/Ginásio Paraense para a educação dos filhos da elite paraense, reforçando o papel do ensino secundário em proporcionar formação de "cultura geral" para os mais bem-nascidos. Por outro lado, para os que se originavam de setores menos favorecidos da sociedade era destinada a formação profissionalizante.

Sobre a formação na perspectiva da cultura geral, também presente no cotidiano educativo da referida instituição paraense, destaca-se o ensino de latim, que, conforme apontado no excerto anterior, foi excluído do currículo pela Reforma Francisco Campos das primeiras séries do ciclo fundamental, sendo ministrado apenas nos anos finais desse ciclo. Já no curso complementar, o idioma era ensinado nos dois anos previstos para a conclusão desse ciclo (Dallabrida, 2009).

Portanto, ainda que tenha sido suprimido pela legislação, o ensino de latim continuou a ser ministrado no colégio/ginásio, pois o ensino de idiomas (inglês, francês etc.), era um traço muito particular da proposta do secundário pautada na chamada educação desinteressada, que prezava pela formação erudita sem finalidades profissionais.

Entretanto, vale ressaltar que, ainda que permanecesse no currículo da instituição e de outros colégios e ginásios caracterizando a educação de base amplamente humanística, o ensino de línguas clássicas como o latim foi seriamente criticado em virtude de as reformas no período da República buscarem modernizar o nível secundário com a inclusão de disciplinas científicas. Nessa perspectiva, Souza (2009) destaca que o latim ainda compunha o programa do secundário, mas sofria críticas contundentes daqueles que defendiam maior cientificidade na instrução secundária.

Além do latim, o grego também era tido como língua obrigatória nesse nível de formação, porém, foi eliminado do currículo ainda em 1915 pela Reforma Maximiliano, por meio do Decreto $n^{\circ} 11.530 / 1915$. O latim, no entanto, sobreviveu à exclusão, em virtude do reconhecimento de sua necessidade e competência na formação da alta cultura (Souza, 2009).

Outro argumento para a manutenção do latim na formação secundarista era que o idioma se configurava como o fundamento da cultura geral, por ser historicamente considerado representante da civilidade e, portanto, aprendê-lo seria fundamental, pelo contexto de formação culta pressuposto pelo secundário. De acordo com Souza (2009), desde o início do século XX defendia-se o aprendizado de latim.

Muitos educadores na primeira metade do século XX continuariam a reafirmar a importância do Latim como essência da formação intelectual e como a base da cultura geral a ser transmitida aos jovens estudantes secundaristas. Além disso, nas representações da época, o Latim possuía outras utilidades, como o valor estético, histórico e cultural. (Souza, 2009, p. 75-76) 
A representatividade atribuída a essa língua clássica foi consolidada pelas reformas dos governos de Getúlio, tanto pela Reforma Francisco Campos como pela Lei Orgânica, com a particularidade de que a primeira reforma direcionava as lições de latim para os alunos que desejavam ingressar no curso de direito (Dallabrida, 2009). A manutenção do ensino de latim por todo o período da Era Vargas também se fez presente na realidade do Colégio Paes de Carvalho/ Ginásio Paraense.

A presença do latim no currículo do secundário do Colégio Paes de Carvalho/Ginásio Paraense pode ser comprovada por um exemplo, do ano de 1944, dos horários de provas da instituição, como demonstra o Quadro 1.

Quadro 1 - Horários de prova do Colégio Paes de Carvalho, outubro de 1944.

\begin{tabular}{|l|c|c|c|}
\hline \multicolumn{4}{|c|}{$2^{\circ}$ ciclo - dia 14} \\
\hline Hora & Disciplina & Série & Turma \\
\hline \multirow{3}{*}{1} & Física & $1^{\mathrm{a}}$ & $1^{\circ} \mathrm{Cl}$ \\
& Geografia geral & $1^{\mathrm{a}}$ & $2^{\circ} \mathrm{Cl}$ \\
\hline 2 & Português & $2^{\mathrm{a}}$ & $\mathrm{Cls}$ \\
\hline 3 & Francês & $2^{\mathrm{a}}$ & $3 \mathrm{Cl}$ \\
& Latim & $1^{\mathrm{a}}$ & $\mathrm{Cls}$ \\
\hline & História Geral & $2^{\mathrm{a}}$ & $2^{\circ} \mathrm{Cl}$ \\
& Latim & $3^{\mathrm{a}}$ & $\mathrm{Cls}$ \\
\hline
\end{tabular}

Fonte: Colégio Paes de Carvalho (1944)

Assim, a importância e permanência do latim no ensino secundário ainda no período da República pode ser corroborada pelo horário de prova descrito acima. Outro fator que chama a atenção trata da disposição de mais de um horário para a aplicação de exames dessa língua. Tal fato pode ser justificado em razão de que, no ano de 1944, o nível secundário já estava sob a vigência da lei orgânica, que também manteve o ensino de latim, reforçando, mais uma vez, a pretensão do ensino secundário: "Uma concepção de educação secundária fortemente associada a um critério de diferenciação social" (Souza, 2009, p. 76).

Ademais, na organização da lei orgânica de 1942, o latim era ofertado nos cursos ginasial e colegial, dividido nos cursos clássico e científico. Isso pode ser evidenciado pelo horário de provas, acima exibido, que se refere aos dois ciclos principais do secundário. A oferta de latim, assim como de grego, no ciclo colegial se dirigia apenas para o curso clássico. O horário de prova do colégio/ginásio também revela a presença de outras disciplinas pertencentes à área das humanidades como história, geografia e línguas estrangeiras, reforçando o predomínio da essência humanística no currículo dessa instituição como resultado da Reforma Capanema, que resgatou o caráter formativo humanista do ensino secundário.

Em relação à disciplina de História, constavam no currículo do Colégio/ Ginásio Paraense, até 1931, as disciplinas História do Brasil e História Universal. Depois da Reforma Francisco Campos, a direção da instituição aglutinou as duas disciplinas que resultaram na cadeira de História da Civilização, conforme trecho 
do documento enviado pela direção ao interventor informando-o de que, a partir de então, a cadeira dessa disciplina funcionaria assim: "Ao professor de história do Brasil, cadeira fundida com a de história universal sob o título de história da Civilização, entregar-se-ia a missão de lecionar essa nova matéria no $2^{\circ}$ anno, sem acarretar maiores despezas" (Gymnasio Paraense, 1931).

A justificativa de fusão das cadeiras de História para a contenção de gastos também se assemelha à situação da exclusão da cadeira de latim. A combinação dessas cadeiras foi a solução para que a instituição secundária paraense pudesse satisfatoriamente continuar suas atividades na instrução da população jovem do estado, educando-os dentro dos cânones do ensino secundário.

As cadeiras de História do Ginásio Paraense/Colégio Paes de Carvalho foram novamente separadas na década de 1940. Com a Reforma Capanema, a cadeira de História do Brasil retorna ao programa curricular junto à cadeira de História Geral. Ambas estavam presentes nos ciclos ginasial e colegial, de acordo com o previsto na legislação e conforme o horário de provas anteriormente apresentado, que mostra o dia de avaliação de História Geral para os alunos do curso colegial.

Apesar da característica humanística predominante, também podemos observar, no mesmo quadro de horários de prova, a existência de disciplinas científicas, como física. A inserção de estudos científicos no currículo do Colégio Paes de Carvalho/Ginásio Paraense foi fruto da Reforma Francisco Campos, que contemplou todos os estabelecimentos secundários do país e estabeleceu o processo de modernização da instrução secundária.

A modernização prevista pela referida reforma pretendia preparar a juventude para que estivesse apta a enfrentar as adversidades da modernidade e a ciência seria o melhor caminho para isso, atribuindo o caráter utilitário ao ensino secundário (Souza, 2008). Contudo, esse processo foi interrompido pela Reforma Capanema, que

deu ênfase ao estudo do Latim ensinado em todas as séries do curso ginasial enquanto as ciências foram relegadas apenas a duas aulas semanais nas duas últimas séries desse ciclo, conforme se observa no quadro abaixo. Nesses termos, a reforma Capanema pode ser considerada uma vitória dos defensores do currículo humanista, o último reduto da língua latina na educação secundária e da valorização da cultura geral como eixo central da formação da juventude. (Souza, 2009, p. 81)

Do conjunto das práticas educativas do Colégio Paes de Carvalho/Ginásio Paraense discutidas até o momento, além das curriculares, também se faz necessário assinalar outras atividades que estavam em harmonia com o cenário nacional no período investigado e eram exercidas nessa instituição. Entre elas, podemos assinalar ações como a premiação de alunos no início do ano letivo, entre outras, que incentivavam o patriotismo e a civilidade.

Os prêmios eram distribuídos no início de cada ano letivo durante uma cerimônia solene em que eram entregues gratificações que homenagea- 
vam políticos do estado ou algumas ilustres figuras do cenário educacional paraense da época. O convite de reabertura do ano letivo de 1945 do Colégio/ Ginásio anunciava:

Realiza-se hoje às 9 horas, a sessão solene de reabertura das aulas do ano letivo de 1945 [...] Serão distribuídos os seguintes premios de acordo com a Portaria da Diretoria:

I- Coronel "Magalhães Barata" - aluna Maria Clementina Pena Frota de Almeida

II- "Bernardino de Sousa Franco" - aluno Clodoaldo Fernando Ribeiro Beckman

III- "Dr. Pais de Carvalho" - aluno Paulo Cesar de Oliveira

IV- "Dr. Amazonas Figueiredo" - aluna Dea da Silva Lira

V- "Dr. Honorato Filgueiras" - Beatriz de Araujo Santos e Lúcia de Araujo Santos. (Colégio Paes de Carvalho, 1945, p. 1)

Outra atividade que também promovia a distribuição de prêmios aos alunos era a exposição de desenho, um evento promovido pelo estado que gratificava os melhores trabalhos dos alunos de diversas instituições escolares públicas e privadas, entre as quais estava o Colégio Paes de Carvalho/Ginásio Paraense. Nesse caso, a premiação era em dinheiro subdividida nas categorias de: primeiro prêmio, segundo prêmio e terceiro prêmio, que variavam entre $100 \$$ e $10 \$$. O aluno do Colégio Paes de Carvalho/Ginásio Paraense ficou com o terceiro prêmio, conforme aponta um trecho da mensagem de 1930 do governador do estado do Pará ao Poder Legislativo, Eurico de Freitas Vale, que informou que naquele ano:

Foi de 2.274 o numero de trabalhos apresentados por esses estabelecimentos e acceitos pela commissão de admissão préviamente nomeada para esse fim. [...] Os premios em dinheiro foram conferidos aos expositores seguintes. Primeiro premio 100\$, Victor Soeiro, do Instituto Lauro Sodré; Segundo premio - 50\$, Maria Vianna Paiva do grupo escolar Barão do Rio Branco [...] terceiro premio - 10\$, Armando Menezes, Gymnasio "Paes de Carvalho". (Pará, 1930, p. 90)

A distribuição de prêmios não se restringia apenas ao ensino primário porque tinha o intuito de gratificar os melhores desempenhos dos alunos, independentemente do ciclo escolar, assim como celebrar solenemente os momentos de fim dos períodos letivos na Primeira República. Na escola secundária, a ação também era tida como importante, já que o ideário educativo do ensino secundário se relacionava à cultura e à civilização e se esperava o melhor desempenho dos alunos.

De acordo com Souza (2008), igualmente como ocorria no nível primário, as cerimônias do ano letivo existentes no ensino secundário eram permeadas por discursos, programas literários, presença de autoridades e das famílias, bem como distribuição de prêmios e colações de grau. Ao lado disso, vale reiterar a questão da civilidade e do valor à pátria pontuada anteriormente, pois essas temáticas também 
eram bastante abordadas no ensino primário e na instrução secundária, especificamente no período do estudado, pois o governo de Getúlio Vargas incentivava a tônica do nacionalismo.

De acordo com Brito (2006), o projeto de educação materializado pelo ministério competente na Era Vargas tinha a característica "nacionalizante da educação" e essa particularidade, segundo a mesma autora, culminou na construção de um discurso voltado à valorização da nacionalidade e da brasilidade ${ }^{7}$.

A nacionalidade e a valorização da pátria podem ser relacionadas à educação militar que compôs o currículo do nível secundário, incluindo o do Colégio Paes de Carvalho/Ginásio Paraense, e estava sob a responsabilidade do então Ministério de Guerra (Brito, 2006).

Essa mesma logística de educação militar foi identificada nessa instituição secundária paraense, sendo descrita pelo governador do estado do Pará, em mensagem do ano de 1930 à assembleia legislativa, frisando que: "A instrucçao militar foi regularmente dada sob a direçao de um inferior do Exército, tendo a 24 de Junho prestado juramento à Bandeira uma grande turma” (Pará, 1930, p. 95).

Uma última questão a ser levantada nesta discussão está relacionada ao outro papel dimensionado à educação no período do governo de Vargas, que seria, conforme aponta Brito (2006), a relevância da educação, isto é, da escola em todos os seus níveis como caminho para a construção da sociedade brasileira. E, portanto, as instituições educativas seriam fundamentais para isso.

O Colégio Paes de Carvalho/Ginásio Paraense não estava alheio a esse cenário. O interventor federal Coronel Joaquim de Magalhães Barata já havia destacado o valor da educação, no relatório destinado ao presidente da República no ano de 1944, enfatizando que a instituição secundária paraense recebe toda a atenção necessária de sua interventoria, em virtude de que ele tem na educação meio fundamental para construção de uma população instruída, promotora dos valores morais. Nas palavras do interventor: "O Colégio Estadual Paes de Carvalho, que é o mais antigo estabelecimento de ensino secundário do Estado, tem merecido do meu govêrno os maiores cuidados, no sentido de ver restabelecida a sua antiga tradição de ordem e moralidade no ensino" (Pará, 1944, p. 169).

Por fim, como podemos notar, o Colégio Paes de Carvalho/Ginásio Paraense sempre esteve ajustado às reorganizações do ensino secundário durante o período investigado, seguindo as atualizações curriculares que oscilaram entre a formação nos estudos científicos e a formação predominantemente humanística, a fim de manter a tradição histórica desse nível de ensino. $\mathrm{E}$ isso evidencia que suas práticas educativas continuaram acompanhando a realidade educacional brasileira até mesmo durante o período de expansão do ensino secundário, compreendido entre as décadas de 1940 e 1960.

7 Destacamos, aqui, esse ponto apenas como breve conhecimento do contexto sócio-político-educacional entre os anos de 1930 e 1945, além da questão do nacionalismo e sua abordagem na educação, assim como a valorização da pátria. Para maior aprofundamento, ver Brito (2006). 


\section{CONSIDERAÇÕES FINAIS}

Diante dos resultados das análises das fontes documentais, podemos ratificar a importância do ensino secundário público para a história da educação por razões como ter um rico histórico de práticas que se originam desde o período colonial, com a Companhia de Jesus e seus padres como pioneiros na formação escolar da população daquela época. A instrução secundária orientada pelo Ratio Studiorum, destinada aos filhos dos colonos, procurava educar a partir das bases humanísticas, procurando incutir naqueles a cultural geral.

Essa finalidade permaneceu durante o Império, que inicialmente ofertava o ensino secundário de maneira difusa por meio das aulas régias, posteriormente institucionalizado a partir da fundação do Colégio Pedro II. Outra questão relevante na história se refere ao período da República, pois, nesse momento, o secundário foi submetido a reformas que tanto buscavam modernizá-lo como mantê-lo alicerçado nas bases humanísticas. Destacam-se, respectivamente, as Reformas Francisco Campos e Gustavo Capanema.

No que diz respeito ao ensino secundário no Pará, o Colégio Paes de Carvalho/Ginásio Paraense foi a primeira instituição pública que procurou educar a juventude paraense. Articulava essa formação com base na legislação nacional e disponibilizava, durante o período investigado, a instrução com um currículo modernizado que oferecia disciplinas científicas, como a física.

Ainda, observamos que o currículo do Colégio Paes de Carvalho/Ginásio Paraense retomou a perspectiva humanística, em conformidade com a Lei Orgânica do Ensino Secundário, no início dos anos 1940. Teve como principal marcador dessa característica o latim, que, ao lado das demais disciplinas que pertenciam ao repertório das humanidades, materializava a educação destinada a construir a cultura e o refinamento intelectual. E esse ponto pode ser evidenciado pelo horário de provas do colégio paraense, que era, em sua maioria, composto pelas humanidades tanto no curso ginasial quanto no colegial.

Em conjunto com essa realidade, o Colégio Paes de Carvalho/Ginásio Paraense aliou a educação desinteressada ao espírito nacionalista e de valorização da pátria em voga no governo de Getúlio Vargas. O reflexo desse espírito era notado em práticas como a premiação aos melhores alunos, pois o seu bom desempenho era esperado e compreendido como o melhor para a nação naquele momento.

No mais, podemos constatar que o Colégio Paes de Carvalho/Ginásio Paraense esteve inserindo em todo o contexto de modificações a que o ensino secundário foi submetido, desde a sua fundação como liceu até o período da República, em que suas práticas ainda apresentavam fundamentos humanísticos ladeados por disciplinas científicas com elementos nacionalistas concernentes ao ideário educacional da Era Vargas.

\section{REFERÊNCIAS}

ARAÚJO, I. H. T. V. A disciplina escolar matemática no Gymnasio Paes de Carvalho durante a Primeira República. 2017. 269f. Tese (Doutorado em Educação) - Universidade Federal do Pará, Belém, 2017. 
BRASIL. Decreto no 19.890, de 18 de abril de 1931. Dispõe sobre a organização do ensino secundário. Brasil, 1931. Disponível em: http://www.planalto.gov.br/ccivil_03/ decreto/1930-1949/D19890.htm. Acesso em: 14 set. 2019.

BRASIL. Decreto-Lei no 4.244, de 9 de abril de 1942. Lei Orgânica do Ensino Secundário. Brasil, 1942. Disponível em: http://www.planalto.gov.br/ccivil_03/decretolei/1937-1946/Del4244.htm. Acesso em: 14 set. 2019.

BRITO, S. H. A. Educação no projeto nacionalista do primeiro governo Vargas (19301945). In: LOMBARDI, J. C. (org.). Navegando na história da educação brasileira. São Paulo: EDFE-Unicamp, 2006. p. 2-24.

COLÉGIO PAES DE CARVALHO. Horário de provas do $2^{\circ}$ ciclo (colegial), $2^{a}$ prova parcial. Belém: Colégio Paes de Carvalho, out. 1944.

COLÉGIO PAES DE CARVALHO. Convite de reabertura do ano letivo: relação de alunos premiados. Belém: Colégio Paes de Carvalho, 1945.

DALLABRIDA, N. A reforma Francisco Campos e a modernização nacionalizada do ensino secundário. Revista Educação, Porto Alegre,v.32, n. 2, p. 185-191, maio/ago. 2009. FRANÇA, M. P. S. S. A. Raízes históricas do ensino secundário público na Província do Grão-Pará: O Liceu Paraense 1840-1889. 1997. 168f. Dissertação (Mestrado em Educação) - Universidade Estadual de Campinas, Campinas, 1997.

GHIRALDELLI JR., P. História da Educação brasileira. 3. ed. São Paulo: Cortez, 2008.

GYMNÁSIO PARAENSE. Requerimento da direção do Colégio solicitando auxílio ao interventor federal. Belém: Gymnásio Paraense, maio 1931.

NUNES, C. O "velho" e "bom" ensino secundário: momentos decisivos. Revista Brasileira de Educação, Rio de Janeiro, n. 14, p. 35-60, maio/ago. 2000.

PARÁ. Mensagem do governador Eurico de Freitas Vale à Assembleia Legislativa do Pará. Belém, set. 1930.

PARÁ. Mensagem do governador Dr.José Carneiro da Gama Malcher à Assembleia Legislativa do Pará. Belém, jul. 1936.

PARÁ. Relatório apresentado pelo interventor federal Coronel Joaquim de Magalhães Cardoso Barata ao presidente da República. Belém, 1944.

PESSANHA, E. C.; BRITO, S. H. A. Ensino secundário ou educação secundária? Controvérsias e singularidades na escrita de sua História. Série-Estudos, Campo Grande, n. 38, p. 237-250, jul./dez. 2014.

SOUZA, R. F. História da organização do trabalho escolar e do currículo no século XX: (ensino primário e secundário no Brasil). São Paulo: Cortez, 2008.

SOUZA, R. F. A renovação do currículo do ensino secundário no Brasil: as últimas batalhas pelo humanismo (1920-1960). Currículo sem Fronteiras, São Paulo, v. 9, n. 1, p. 72-90, jan./jun. 2009.

ZOTTI, S. A. O ensino secundário no império brasileiro: considerações sobre a função social e o currículo do Colégio D. Pedro II. Revista HISTEDBR On-line, Campinas, n. 18, p. 29-44, jun. 2005. 


\section{SOBRE OS AUTORES}

Tayana Helena Cunha Silva é doutoranda em educação pela Universidade Federal do Pará (UFPA).

E-mail: tayanacunhahcs@gmail.com

Cesar Augusto Castro é doutor em educação pela Universidade de São Paulo (USP). Professor da Universidade Federal do Maranhão (UFMA). E-mail: ccampin@terra.com.br

Conflitos de interesse: Os autores declaram que não possuem nenhum interesse comercial ou associativo que represente conflito de interesses em relação ao manuscrito.

Financiamento: $\mathrm{O}$ estudo não recebeu financiamento.

Contribuições dos autores: Administração do Projeto, Análise Formal, Conceituação, Curadoria de Dados, Escrita — Primeira Redação, Escrita — Revisão e Edição: Cunha Silva, T.H.; Castro, C.A.

Recebido em 14 de abril de 2020 Aprovado em 18 de agosto de 2020 